\title{
PROMOTING EMOTIONAL WELL-BEING THROUGH SCHOOL MENTAL HEALTH SERVICES
}

\author{
Taylor L. Milner \\ Samuel Y. Song
}

\begin{abstract}
The influence of emotion on thoughts, memories, behaviors and everyday decisions is currently being researched across multiple disciplines of psychology. Children and adolescents are not born with the skills needed to regulate their emotions; these skills are something learned over time. However, some children are never properly taught these skills, which can cause difficulties in the school environment because they are more likely to experience problems both academically and behaviorally. This paper explores the possible benefits of offering mental health services in schools that are focused towards promoting emotional health while also developing emotional regulation skills for children. Beginning with the ways in which children learn to express their emotions and the factors that contribute to an inability to express emotion appropriately, to the influence of emotions on academic performance, how emotional regulation skills can benefit academic success, how we can best build these emotional regulation skills in the school setting, discussion of Emotion Regulation Therapy (ERT) which is an example of a service that could be used, the importance of parental involvement when offering these types of services and concluding with possible obstacles that could interfere with the effectiveness of these services in the school setting
\end{abstract}

\section{Keywords}

emotional regulation, school mental health, youth mental health, well-being, affect, Emotional Regulation Therapy (ERT)

\section{Promoting Emotional Well-Being Through School Mental Health Services}

Being consciously aware of our emotions has been found to positively correlate with the ability to make better decisions, recognize and respond to emotion in others and overall leads to higher quality affective experiences. However, his type of emotional 
awareness is not readily available to children. Children have a harder time making sense of their emotions and emotional impulses and with the added pressure of academics, social lives and the hormones that come naturally with aging; it is difficult for some students to manage their emotional health. This can lead to a decrease in motivation, poorer grades, increased behavioral problems in schools and can even impact a student's well being with an increase in internalizing disorders, anxiety, and depression. Allowing for more extensive mental health services, such as Emotion Regulation Therapy (ERT), to be available in schools would give children the opportunity to strengthen their emotion regulation skills and ultimately lead to greater self-awareness, the ability to build better relationships, enhanced communication skills, more logical decision making and an generally heightened sense of self-worth. All of which would benefit student performance, increase academic achievement and decrease both behavioral and academic issues in schools. The purpose of this paper is to explore the factors related to promoting emotional and mental health in schools and how providing services that support emotional health could lead to more positive student outcomes.

\section{Affective Reactions and the Relation Between Awareness and Emotion}

The way we assign value to the various components of our lives and our overall experiences is referred to as affective reactions (Huntsinger \& Schnall, 2013). Individuals go through life making decisions and rating life experiences while simultaneously considering an imaginary spectrum between two extremes. This spectrum is used to measure the "goodness" or the "badness" of something which can externalize in many different ways neurologically, physiologically, cognitively or behaviorally based on what triggered the affective reaction. When several of these reactions occur concurrently, it is referred to as an affective-state which is represented by an emotion (Huntsinger \& Schnall, 2013). Emotions, whether they be conscious or unconscious, have the ability to dictate behaviors, thought processes, recollection of memories and even personal feelings and biases towards certain people or groups.

The relation between awareness and emotion is continuously researched in the field of psychology and neuroscience today. The notion that there is a conscious awareness in our experience of emotion is something highly accepted across platforms, but experiencing an emotion implies that we are aware of it and the feelings which coincide with it (Berridge, 2018). People tend to conflate emotions with subjective feelings which would indicate that we are always consciously aware of them, however, evidence suggests that emotions can also occur unconsciously without there being any subjective feelings present (Berridge, 2018). Since there is a very intimate link between emotion, feeling, experience and awareness, the majority of people find it difficult to decipher which is influencing which during any given time (Gelder \& Tamietto, 2018). So the questions remain; how much influence do our conscious minds actually have? Does being consciously aware of our emotions require a certain amount of emotional intelligence and if so, is this something that can be taught or is it innate? These are important to ask 
when we consider the degree in which emotion influences our judgement and decisionmaking on a daily basis. This is especially prevalent when we contemplate how schoolaged children recognize, control and act on their emotional impulses.

\section{The Role of Nurture in a Child's Ability to Express Emotion}

The conditions in which a child is raised varies amongst individuals. This notion implies that every child is going to witness different forms of emotional expression and emotional interpretation as they grow up. This not only influences, but reflects the way individuals express their emotions as they get older which factors into an individual's ability to consciously perceive not only their own emotions, but how they recognize certain emotions in others. Children who suffered from maltreatment or abuse might feel as though their emotions are not important or valid and in turn, may be unable to or do not feel the need to express them. Maltreatment in children has also been shown to negatively influence the development of regions associated with cognitive control during emotional regulation (Jenness et al., 2020). Not only this, but difficulties with emotional regulation can cause other severe complications during juvenescence such as eating disorders (Vajda \& Lang, 2014), antisocial behaviors, delinquency (Hye-Jin et al., 2016), low levels of self-compassion and even symptoms related to post-traumatic stress (Barlow et al., 2017).

The way we express our emotions is an integral part in how we translate our needs to those around us. Children who endure difficulties with emotional regulation and emotional awareness could potentially have trouble properly recognizing and reacting to those same emotions being expressed by others. Research shows that children who suffer from past abuse or neglect have an impaired development of social cognition and could benefit from therapeutic interventions that improve their interpersonal communications (Koizumi \& Takagishi, 2014). This is important to consider because a child who grew up with emotionally distant parents is not going to be able to express or interpret emotions the same way as someone who grew up in a communicative and emotionally supportive household.

\section{The Influence of Emotion on Academic Success}

Another role of emotion that is important to consider is the influence it has on the academic success of children and their ability to retain and recall the information they learn in school. Difficulties with emotional regulation could potentially be problematic throughout their school careers, but also later on in life without proper support and guidance. Studies show that children with better emotional regulation skills are better equipped to handle the novel demands of the school environment more efficiently than children with poor emotion regulation skills (Harrington et al., 2020). Recent findings in developmental science connecting social, emotional and academic growth has been able to predict 
academic success based on a child's social and emotional development. It has been suggested that advances in social-emotional competencies (SEC) may be a way to promote academic growth because it focuses on the child's development as a whole rather than just teaching academic content. It can also help children acquire a sense of responsibility and knowledge that can ultimately follow them into adulthood (Oberle, 2014).

Based on what we know about emotional awareness, we can imply that being consciously aware of our emotions would suggest that we also have a better chance of being able to control the intensity in which our feelings coexist with certain emotions. This influences our behaviors and the way we react to certain emotional triggers and can also give us the ability to recognize and respond to emotions in others. However, not all children are fortunate enough to have access to the information needed to be taught these skills which diminishes their ability to be able to achieve that level of emotional intelligence. Some individuals may be unable to recognize troubles associated with emotional regulation or issues relating to emotions and even if they do, that does not suggest that they feel comfortable seeking out mental health services.

\section{Building Emotional Regulation (ER) Skills in Schools}

Schools already provide a range of mental health services such as assessment, behavior management, crisis intervention, and counseling. However, improvements still need to be made to ensure these services are accessible and beneficial to the students who need it; especially those who reside in under-developed regions. Studies have shown educators' attitudes are in favor of better resources and training to support student's mental health needs. Educators are concerned that the training and resources currently being offered are not adequate enough to manage and address the mental health needs of their students (Moon \& Mendenhall, 2017).

Schools are an ideal place to provide mental health services to students because not only are they accessible to the majority of children and families, but it is also a natural setting where children feel comfort because it's a significant part of their daily routine. The school environment also allows for teachers and administration to observe students and develop close relationships with them which could help in referring those who might need access to mental health services. However, as the mental health crisis continues to grow and become more noticeably prevalent in schools, the less equipped teachers and administrators are to support student's needs.

Helping students develop a sense of emotional awareness will ultimately decrease their risk of developing internalizing disorders such as depression (Beveren et al., 2018), obsessive-compulsive phenomena (Berman et al., 2018), anxiety (Renna et al., 2017) and help to support an increase in emotional intelligence. Studies have shown that emotional regulation is a key underlying mechanism in emotional awareness which is also a basic skill required for learning adaptive emotional regulation skills. If children are unable to deploy appropriate emotional regulation strategies towards negative 
emotions, the effects can appear long-term since the stressors ultimately remain unresolved (Beveren et al., 2018). These mental health demands emphasize a need for providing support in which students can learn emotional regulation skills, such as Emotion Regulation Therapy (ERT).

\section{What is Emotion Regulation Therapy (ERT)?}

Emotion Regulation Therapy (ERT) is a manual-based therapy that utilizes various approaches and treatments such as cognitive-behavioral, mindfulness-based, experiential, acceptance and emotion focused; all of which use a framework that was created from the most relevant and translational findings in affect science. Emotion Regulation Therapy (ERT) focuses on training major emotion regulation skill groups such as attention, allowance, distancing and reframing where the skills are taught in the first half of treatment and then later on practiced by clients in an exposure or behavioral activation phase during the second half of the treatment. Emotion Regulation Therapy (ERT) has been linked to decreased measures of generalized anxiety disorder (GAD) and other symptoms associated with anxiety and depression. ERT has also shown positive correlations with an overall improved quality of life (Mennin \& Fresco, 2020). The ultimate goal of offering ERT in schools would be to help students to better recognize and identify complex emotions and teach them skills they need to manage them accordingly while also having an increased acceptance of affective experiences and the ability to identify needs in oneself and others. This also would lead to an increase in student motivation towards academics, a decrease in the use of emotional avoidance strategies and an increased ability to make well thought-out decisions while also creating and managing interpersonal relationships.

The traditional model of ERT is currently a manualized intervention consisting of 16 weekly sessions that specifically target motivational mechanisms, regulatory mechanisms, behavioral responses, and contextual learning consequences that are hypothesized to negatively correlate with distress orders such as anxiety and depression (Renna et al., 2017). ERT is divided into two phases of treatment, the first phase focusing on cultivating mindful emotion regulation skills and promoting conscious and flexible responses to intense emotions experiences such as anger, anxiety and sadness. The second phase focuses on promoting behavioral "proactivity" which allows clients the ability to utilize their new skills and apply them to real-world situations which before might have promoted a sense of anxiety or depression (Renna et al., 2017).

Currently there is no single assessment device used in ERT, but throughout treatment therapists render a clinical impression to the degree in which a client endorses intense emotions, narrows their focus on security to the exclusion of reward (motivational mechanisms), engages in reactive responses in order to avoid intense emotions (regulatory mechanisms) and how it in turn diminishes their pursuit of a potentially rewarding experience (contextual learning consequences). Therapists also track and revise their impressions of what they believe to be the degree in which a client is demonstrating 
mindful awareness of their emotions and motivations, the regulation of their emotions and their ability to pursue actions which are reflective of meaningful rewards or value. Clients are also required to complete a brief standardized self-report battery prior to each session so that the therapist has the ability to capture a dynamic assessment in affective changes such as worry, rumination, anxiety, depression, attention regulation, decentering, and reappraisal throughout the treatment (Renna et al., 2017).

Figure 1 Conceptual model of target mechanisms, change principles, and therapeutic processes in Emotion Regulation Therapy

Target Mechanisms

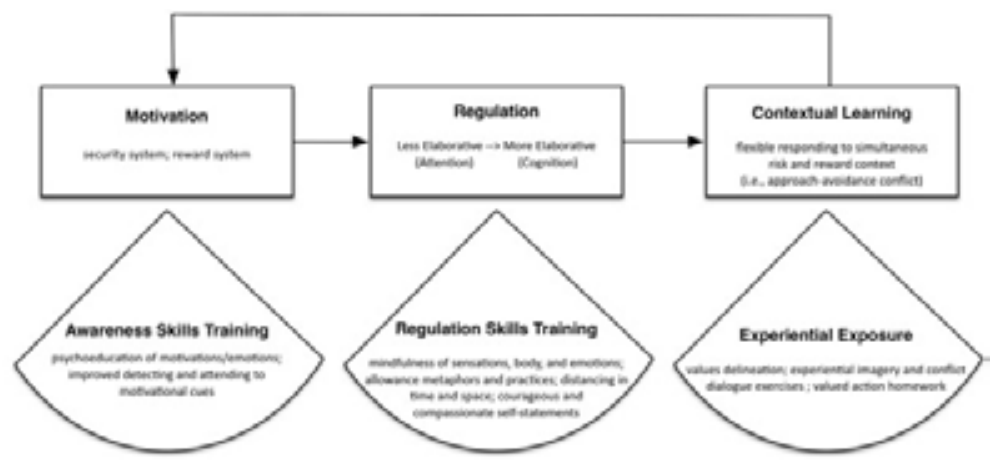

Source: Renna et al. (2017)

\section{Parental Involvement in Emotional Support Services}

In order for any service geared towards emotional well-being to be successful in the school environment, it is important that parents are on board. Emotional regulation and associated autonomic activation is developed throughout childhood and adolescence under the influence of the family environment and the effect of parental emotional socialization (Witte et al., 2016). Parental involvement in education can be viewed as a multidimensional construct consisting of multiple levels such as school involvement, home involvement and academic socialization (Wang \& Sheikh-Khalil, 2013). Studies show that the amount of parental involvement in regards to a child's educational experience can be a predictor of not only a student's academic success, but also the state of a student's mental health (Wang \& Sheikh-Khalil, 2013). Parental factors are also noted to have an influence on childhood depression and internalizing problems (Yap \& Jorm, 2015) suggesting that parents could seemingly be unaware of how their actions are being perceived by their children and the influence those actions have on their emotional state. This type of disconnect between parents and their child's emotional well-being could be a factor in the rise of mental health crises among schoolaged children. It is important that parents be involved in the child's initial diagnostic assessment and treatment. 


\section{Conclusion}

There are many challenges that could be faced while implementing services geared towards emotional health in a fluctuating environment such as a school. Since schools are publically funded and costs are being cut by the year, it would be difficult to generate the money needed to deliver such services in all the public schools where it is needed. This would also require school psychologists to have the proper training and time to implement services like this and since there is currently a shortage of school psychologists and many are covering more than one school in their workday, this may prove difficult. There is also a possibility that parents do not want to actively participate in the treatment process and/ or are not supportive of these types of services being offered in schools. This could make it difficult to get acceptance from the school community.

Despite the challenges, providing services that focus on promoting emotional health as well as support children in developing proper emotional regulation skills could help students succeed both academically and socially while also resolving many behavioral and academic problems. This gives students the opportunity to evolve a more powerful sense of emotional awareness which could in turn, help them thrive in all aspects of life as they continue to grow and mature.

\section{References}

Barlow, M. R., Turow, R. E., \& Gerhart, J. (2017). Trauma appraisals, emotion regulation difficulties, and self-compassion predict posttraumatic stress symptoms following childhood abuse. Child Abuse \& Neglect, 65, 37-47. doi: 10.1016/j.chiabu.2017.01.006

Berman, N. C., Shaw, A. M., Curley, E. E., \& Wilhelm, S. (2018). Emotion regulation and obsessive-compulsive phenomena in youth. Journal of Obsessive-Compulsive and Related Disorders, 19, 44-49. doi: 10.1016/j.jocrd.2018.07.005

Berridge, K. C. (2018). Affect is essential to emotion. In Fox, A. S., Lapate, R. C., Shackman, A. J. \& Davidson, R. J. (Eds.) (2018). The nature of emotion: Fundamental questions. New York: Oxford University Press.

Beveren, M. V., Goossens, L., Volkaert, B., Grassmann, C., Wante, L., Vandeweghe, L. et al. (2018). How do I feel right now? Emotional awareness, emotion regulation, and depressive symptoms in youth. European Child \& Adolescent Psychiatry, 28(3), 389398. doi: 10.1007/s00787-018-1203-3

Gelder, B. \& Tamietto, M. (2018). What is the role of unconscious emotions and conscious awareness in emotion? In Fox, A. S., Lapate, R. C., Shackman, A. J. \& Davidson, R. J. (Eds.) (2018). The nature of emotion: Fundamental questions. New York: Oxford University Press. 
Harrington, E. M., Trevino, S. D., Lopez, S. \& Giuliani, N. R. (2020). Emotion regulation in early childhood. Implications for socioemotional and academic components of school readiness. Emotion, 20(1), 48-53. doi: 10.1037/emo0000667

Huntsinger, J. R. \& Schnall, S. (2013). Emotion - Cognition Interactions. Oxford Handbooks Online. doi: 10.1093/oxfordhb/9780195376746.013.0036

Hye-Jin, K., Ho, K. Y., Jung, K. Y., Kihyun, K., Moon, Y. D., Hyein, C. et al. (2016). 5.48 Association Between Experience Of Child Abuse And Factors Of Emotional Regulation, Antisocial Behavior Of Children In Detention Centers And Correctional Facilities. Journal of the American Academy of Child \& Adolescent Psychiatry, 55(10). doi: 10.1016/j. jaac.2016.09.306

Jenness, J. L., Peverill, M., Miller, A. B., Heleniak, C., Robertson, M. M., Sambrook, K. A. et al. (2020). Alterations in neural circuits underlying emotion regulation following child maltreatment: A mechanism underlying trauma-related psychopathology. Psychological Medicine, 1-10. doi: 10.1017/s0033291720000641

Jones, J. D., Boyd, R. C., Calkins, M. E., Ahmed, A., Moore, T. M., Barzilay, R. et al. (2019). Parent-Adolescent Agreement About Adolescents' Suicidal Thoughts. Pediatrics, 143(2). doi: 10.1542/peds.2018-177

Koizumi, M. \& Takagishi, H. (2014). The Relationship between Child Maltreatment and Emotion Recognition. PLOS ONE, 9(1). doi: 10.1371/journal.pone.0086093

Mennin, D. S. \& Fresco, D. M. (2020). About. Emotion Regulation Therapy. Retrieved from www.emotionregulationtherapy.com/our-practice.

Moon, J., Williford, A. \& Mendenhall, A. (2017). Educators' perceptions of youth mental health: Implications for training and the promotion of mental health services in schools. Children and Youth Services Review, 73, 384-391. doi: 10.1016/j.childyouth.2017.01.006

Oberle, E., Schonert-Reichl, K. A., Hertzman, C. \& Zumbo, B. D. (2014). Social-emotional competencies make the grade: Predicting academic success in early adolescence. Journal of Applied Developmental Psychology, 35(3), 138-147. doi: 10.1016/j. appdev.2014.02.004

Renna, M. E. et al. (2017). Emotion Regulation Therapy: A Mechanism-Targeted Treatment for Disorders of Distress. Frontiers in Psychology, 8. doi: 10.3389/fpsyg.2017.00098

Renna, M. E., Seeley, S. H., Heimberg, R. G., Etkin, A., Fresco, D. M. \& Mennin, D. S. (2017). Increased Attention Regulation from Emotion Regulation Therapy for Generalized Anxiety Disorder. Cognitive Therapy and Research, 42(2), 121-134. doi: 10.1007/s10608017-9872-7 
Vajda, A. \& Lang, A. (2014). Emotional Abuse, Neglect in Eating Disorders and their Relationship with Emotion Regulation. Procedia - Social and Behavioral Sciences, 131, 386-390. doi: 10.1016/j.sbspro.2014.04.135

Wang, M. \& Sheikh-Khalil, S. (2013). Does Parental Involvement Matter for Student Achievement and Mental Health in High School? Child Development, 85(2), 610-625. doi: $10.1111 /$ cdev. 12153

Witte, N. A., Sütterlin, S., Braet, C. \& Mueller, S. C. (2016). Getting to the Heart of Emotion Regulation in Youth: The Role of Interoceptive Sensitivity, Heart Rate Variability, and Parental Psychopathology. PLOS ONE, 11(10). doi: 10.1371/journal.pone.0164615

Yap, M. B. H. \& Jorm, A. F. (2015). Parental Factors Associated with Childhood Anxiety, Depression, and Internalizing Problems: A Systematic Review and Meta-Analysis. Journal of Affective Disorders, 175, 424-440. doi: 10.1016/j.jad.2015.01.050

\section{Authors}

Taylor L. Milner

Counselor Education, School Psychology, and Human Services University of Nevada, Las Vegas

4505 S. Maryland Pkwy., Las Vegas, NV 89154, United States

milnet1@unlv.nevada.edu

Samuel Y. Song

Counselor Education, School Psychology, and Human Services University of Nevada, Las Vegas

4505 S. Maryland Pkwy., Las Vegas, NV 89154, United States

sam.song@unlv.edu 